\title{
To Assess the Factor Responsible for Episiotomy Wound Healing Among Post Natal Mother
}

\author{
Shalini Moon ${ }^{1}$, Priyanka Timande 2 , Sneha Gedam², Poonam \\ Golhar ${ }^{2}$, Ashish Lokhande', and Ashwini Hude ${ }^{2}$ \\ ${ }^{1}$ Smt. Radhikabai Meghe Memorial College of Nursing, Datta Meghe Institute of \\ Medical Sciences (Deemed to be University) Sawangi (Meghe) Wardha, India \\ ${ }^{2}$ Basic B. Sc. Nursing Student, Smt. Radhikabai Meghe Memorial College of Nursing, Datta Meghe \\ Institute of Medical Sciences (Deemed to be University) Sawangi (Meghe) Wardha, India \\ Corresponding author email: moonshalini@gmail.com
}

\section{ABSTRACT}

Pregnancy is a long and very exciting special journey for an antenatal woman. Maternity services should support the mother, her baby and her family during this journey with a view not only to their short-term safety but also to their long-term well being (UK Department of Health 1993).Objectives: 1. To assess the factors responsible for episiotomy wound healing among postnatal mother. 2. To associate the assessment of level of healing of episiotomy wound among postnatal mothers with selected demographic variables. Present quasi experimental quantitative study was conducted to assess the factors responsible for episiotomy wound healing among postnatal mothers. 60 subjects were selected based on the inclusion and exclusion criteria and non-probability convenience sampling technique. Structured observational checklists were used as tools to collect the data. The analysis of data shows 71.66\% of the postnatal mothers of anaemia, $10 \%$ of the have vulvovaginitis, $23.33 \%$ of had urinary tract infection, 1.66\% of had surgical site infection, $8.33 \%$ of had perineal tear, $6.66 \%$ of had before episiotomy, 100\% of had after episiotomy, 1.66\% of had obesity, $11.66 \%$ of had hypothyroidism, 6.66\% of had diabetes mellitus, 16.66 of had hypertension, 83.33\% of had edema. The discomfort of episiotomy is an added concern in the already overstressed situation. Episiotomy, despite evidence that it is an unnecessary intervention, is one of the most common surgical procedures performed during the second stage of labour especially in Primigravida women. Perineal trauma due to episiotomy causes a number of distressing conditions in the postnatal period. It causes pain, discomfort, disturbed normal activities; it gives the mother a feeling of inadequacy, increased the risk of infection, prolongs postnatal recovery and increased the cost of healthcare. After the detailed analysis, this study the study shows various risk factors affects the health status of postnatal mother and need to focus on that to improve health status of PNC mother after delivery.

\section{KEY WORDS: ASSESS, EPISIOTOMY, POSTNATAL MOTHERS AND WOUND HEALING.}

\section{INTRODUCTION}

In a dynamic society where values, rules and practices concerning childbearing and rearing are changing rapidly, women and their families seek guidance from many sources. However, women rely on maternity nurses to provide specific, accurate and appropriate information

Biosc Biotech Res Comm P-ISSN: 0974-6455 E-ISSN: 2321-4007

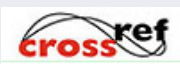

Identifiers and Pagination

Year: 2021 Vol: 14 No (5) Special Issue

Pages: $333-342$

This is an open access article under Creative

DOI: http://dx.doi.org/10.21786/bbrc/14.5/57
Commons License Attribn 4.0 Intl (CC-BY). about what they should expect and request from the health care system, and about what choices they have regarding their own care. For some years now, there has been increasing pressure on midwifery and other allied health care professions to make clinical practice more firmly grounded on research evidence rather than on time - honored ritual, on the basis that patient care and the profession's status can only be enhanced through the development and implementation of relevant, scientifically derived findings. (Hicks Carolyn, 1994). The report of the committee on nursing encouraged the pursuit of research and Research Mindedness: Individual accountability requires maternity nurses to examine the care they provide, It is therefore, important that maternity nurses have access to reliable research based knowledge.

\section{Article Information}

Received: $28^{\text {th }}$ Mar 2021 ccepted after revision: 30 $0^{\text {th }}$ May 2021 
Since 1975, there has been an increase in the number of studies, in investigation midwifery practice, (Haris, 1992).

A complex series of events occur with child-birth. One such event is the practice of episiotomy, which has undergone changes in popularity, with rationale for clinical practice not always based upon available scientific evidence. Perineal injury, including episiotomy, has long been accepted as a standard outcome of vaginal delivery. Episiotomy defined as an incision of the perineum during delivery to enlarge the vaginal orifice, has been, in practice since 1742 , when a perineal incision was used to facilitate difficult deliveries. However, episiotomy did not become common until the early 1900s when the shift from home to hospital delivery occurred. The popularity of episiotomy among obstetricians continued to grow with the introduction of local anaesthetic and suture material and as a result of advocacy for its performance by two obstetricians, DeLee and Pomeroy (Maier, 1997). It was claimed that an episiotomy should be performed for every women delivering her first child to avoid perineal lacerations and damage to the pelvic floor. The prevention of perineal trauma is very much at the forefront of midwifery care. It gives many midwives a sense of pride to complete a birth with no perineal trauma. However, this should not be at the expense of trauma to the vaginal mucosa. Episiotomy rates up to $100 \%$ have been reported and vary among countries and institutions.

Episiotomy is one of the most widely practiced obstetric procedures and refers to a surgical incision on the perineum during the second stage of labor to enlarge the diameter of the vulval outlet to facilitate passage of the fetal head and prevent an uncontrolled tear of the perineal tissue. Indications such as a prolonged second stage, macrosomia, non-reassuring fetal heart rate, instrumental delivery, occiput posterior position, and shoulder dystocia have been questioned. The incision substantially increases maternal blood loss, the average depth of posterior perineal injury, risk of anal sphincter damage, improper wound healing and increased amount of pain in the immediate postpartum period. Episiotomy at the first vaginal birth significantly and independently increases the risk of repeated episiotomy and spontaneous tears in subsequent delivery. Routine episiotomy is now considered to be a form of obstetric violence when a woman is automatically transformed into a patient and when routine medical procedures are carried out without giving the woman the right to make her own decisions concerning her own body.

\section{Objectives:}

1. To assess the factors responsible for episiotomy wound healing among postnatal mother.

2. To associate the assessment level of healing of episiotomy wound among postnatal mothers with selected demographic variables.

\section{Assumption:}

1. The risk factors of episiotomy may be responsible for delayed healing of episiotomy wound in most of the postnatal mothers.

\section{Research Hypothesis:}

H1- There will be significant association in the risk factors responsible for episiotomy wound healing among postnatal mother with their selected demographic variable.

\section{MATERIAL AND METHODS}

Present quasi experimental quantitative study was conducted to assess the factors responsible for episiotomy wound healing among postnatal mothers. 60 subjects were selected based on the inclusion and exclusion criteria and non-probability convenience sampling technique. Structured observational checklists were used as tools to collect the data.

Criteria for sample selection: Inclusion:-1.Postnatal mothers who have normal vaginal delivery with left mediolateral and Right medio-lateral episiotomy.2. Postnatal mothers within 8 hours of delivery.3. Postnatal mothers who were willing to participate in the study. Exclusion:-1. Postnatal mothers who were having immediate postnatal complications like primary postpartum hemorrhage, shock, amniotic fluid embolism.2. Postnatal mothers who underwent instrumental procedures like forceps or vacuum delivery.

\section{RESULTS}

Descriptive and inferential statistics were used to analyse the collected data. The data finding have been organized and analysed according to the plan for data analysis and are presented under the following sections.

Section-A:- Percentage wise distribution of postnatal mothers according to demoghraphic characteristics.

\section{Section-B:- Assessment of the risk factors responsible} for episiotomy wound healing.

Section-C: Association of episiotomy wound healing score among postnatal mothers with their selected demographic variables.

\section{Section A: Percentage Wise Distribution of Postnatal Mothers According To Their Demographic Characteristics.}

This section deals with percentage wise distribution postnatal mothers with regards to their demographic characteristics. A convenient sample of 60 subjects was drawn from the study population, who were from AVRRH, Sawangi (M), Wardha. The data obtained to describe the sample characteristics including age of the mother, education, area of residence, number of parity, type of delivery, occupation, nutritional pattern, monthly income, type of episiotomy incision, respectively.

The above table shows the distribution of samples 
according to their age. It shows that in frequency for 37 of the samples belongs to the 18-25age group (the percentage score of 61.66\%); in the frequency 21 of the samples belong to the 26-30 age group (the percentage score of 35\%); in the frequency 2 of the samples belong to the 30-35 age group (the percentage score of 3.33\%); Hence it was interpreted that most of the samples under study were between the age group of 18-25 year.

\begin{tabular}{|c|c|c|}
\hline Demoghraphic variables & Frequency & Percentage (\%) \\
\hline \multicolumn{3}{|l|}{ 1. Age (in year) } \\
\hline $18-25$ yrs & 37 & 61.66 \\
\hline $26-30$ yrs & 21 & 35 \\
\hline $30-35$ yrs & 2 & 3.33 \\
\hline $35-40$ yrs & 0 & 0 \\
\hline 40 \&t above & 0 & 0 \\
\hline \multicolumn{3}{|l|}{ 2. Education } \\
\hline Primary & 13 & 21.66 \\
\hline Secondary & 29 & 48.33 \\
\hline Higher secondary & 8 & 13.33 \\
\hline Graduate & 7 & 11.66 \\
\hline Post - graduate $\&$ above & 3 & 5 \\
\hline \multicolumn{3}{|l|}{ 3. Area of residence } \\
\hline Urban & 18 & 30 \\
\hline Rural & 42 & 70 \\
\hline \multicolumn{3}{|l|}{ 4. Occupation } \\
\hline Housewife & 49 & 81.66 \\
\hline Private service & 1 & 1.66 \\
\hline Others & 10 & 16.66 \\
\hline \multicolumn{3}{|l|}{ 5. Monthly income } \\
\hline $5000-10000$ & 31 & 51.66 \\
\hline $10001-15000$ & 15 & 25 \\
\hline $15001-20000$ & 6 & 10 \\
\hline $20001-25000$ & 3 & 5 \\
\hline 30000 \& above & 5 & 8.33 \\
\hline \multicolumn{3}{|l|}{ 6. Number of parity } \\
\hline Primipara & 37 & 61.66 \\
\hline Multipara & 23 & 38.33 \\
\hline \multicolumn{3}{|l|}{ 7. Type of delivery } \\
\hline Spontaneous labour & 44 & 73.33 \\
\hline Induced labour & 16 & 26.66 \\
\hline \multicolumn{3}{|c|}{ 8. Type of episiotomy incision } \\
\hline Mediolateral & 59 & 98.33 \\
\hline Median & 1 & 1.66 \\
\hline \multicolumn{3}{|l|}{ 9. Nutritional pattern } \\
\hline Vegetarian & 43 & 71.66 \\
\hline Mixed(Veg+Nonveg) & 17 & 28.33 \\
\hline
\end{tabular}

The above table shows the distribution of the samples according to their education. It shows that in frequency for 13 of the samples belong to the primary group (the percentage score of 21.66\%); in frequency for 29 of the samples belong to the secondary group (the percentage score of $48.33 \%$ ); in frequency for 8 of the samples belong to the higher secondary (the percentage score of $13.33 \%$ ); in frequency for 7 of the samples belong to the graduate (the percentage score of $11.66 \%$ ); in frequency for 3 of the samples belong to the post-graduate $\mathrm{Ct}$ above (the percentage score of 5\%); hence it was interpreted that most of the samples under study were secondary. The above table shows the distribution samples according to their area of residence. It shows that in frequency for 18 of the samples belongs to the urban area (the percentage score of 30\%); in the frequency for 42 of the samples belongs to the rural area (the percentage score of 70\%); Hence it was interpreted that most of the samples under study were between area of residence of rural area. 
The above table shows the distribution samples according to their occupation. It shows that in frequency for 49 of the samples belongs to the housewife (the percentage score of $81.66 \%$ ); in the frequency for 1 of the samples belongs to the private service (the percentage score of $1.66 \%)$; the frequency for 10 of the samples belongs to the others (the percentage score of 16.66\%); in government service are no representative samples. Hence it was interpreted that most of the samples under study were between occupations of housewife

The above table shows the distribution samples according to their monthly income. It shows that in frequency for 31 of the samples belongs to the 5000-10000 (the percentage score of 51.66\%); in the frequency for 15 of the samples belongs to the 10001-15000 (the percentage score of $25 \%$ ); the frequency for 6 of the samples belongs to the
15001-20000 (the percentage score of 10\%); in frequency for 3 of the samples belongs to the 20001-25000 (the percentage score of 5\%); in the frequency for 5 of the samples belongs to the $30000 \mathrm{Et}$ above (the percentage score of 8.33\%); Hence it was interpreted that most of the samples under study were between monthly income of 5000-10000.

The above table shows the distribution samples according to their number of parity. It shows that in frequency for 37 of the samples belongs to the primipara (the percentage score of 61.66\%); in the frequency for 23 of the samples belongs to the multipara (the percentage score of $38.33 \%$ ); in grandpara are no representative samples ; Hence it was interpreted that most of the samples under study were between number of parity of primipara.

Table 2. Level of assessment of episiotomy wound healing among postnatal mothers

\begin{tabular}{|c|c|c|c|}
\hline Sr.No & $\begin{array}{c}\text { Factors Responsible For } \\
\text { Episiotomy Wound Healing }\end{array}$ & Yes & No \\
\hline \multirow[t]{2}{*}{1.} & Poor Nutrition: & & \\
\hline & $\bullet$ Anaemia & $43(71.66 \%)$ & $17(28.33 \%)$ \\
\hline 2. & $\begin{array}{c}\text { Infection: } \\
\text { - Vulvovaginitis } \\
\text { - Urinary Tract Infection } \\
\text { - Surgical site infection }\end{array}$ & $\begin{array}{c}6(10 \%) \\
14(23.33 \%) \\
1(1.66 \%)\end{array}$ & $\begin{array}{c}54(90 \%) \\
46(76.66 \%) \\
59(98.33 \%)\end{array}$ \\
\hline 3. & $\begin{array}{l}\text { Perineal Injury: } \\
\text { • Perineal Tear } \\
\end{array}$ & $5(8.33 \%)$ & $55(91.66 \%)$ \\
\hline 4. & $\begin{array}{c}\text { Medications: Antibiotic Prophylaxis } \\
\bullet \text { Before episiotomy } \\
\bullet \text { After episiotomy }\end{array}$ & $\begin{array}{l}4(6.66 \%) \\
60(100 \%)\end{array}$ & $\begin{array}{l}56(93.33 \%) \\
\quad 0(0 \%)\end{array}$ \\
\hline 5. & Obesity & $1(1.66 \%)$ & $59(98.33 \%)$ \\
\hline 6. & Hypothyroidism & $7(11.66 \%)$ & $53(88.33 \%)$ \\
\hline 7. & Diabetes Mellitus & $4(6.66 \%)$ & $56(93.33 \%)$ \\
\hline 8. & Hypertension & $10(16.66 \%)$ & $50(83.33 \%)$ \\
\hline 9. & Edema & $50(83.33 \%)$ & $10(16.66 \%)$ \\
\hline
\end{tabular}

The above table shows the distribution samples according to their type of delivery. It shows that in frequency for 44 of the samples belongs to the spontaneous labour (the percentage score of 73.33\%); in the frequency for 16 of the samples belongs to the induced labour (the percentage score of 26.66\%); Hence it was interpreted that most of the samples under study were between type of delivery of spontaneous labour.

The above table shows the distribution samples according to their type of episiotomy incision. It shows that in frequency for 59 of the samples belongs to the mediolateral (the percentage score of 98.33\%); in the frequency for 1 of the samples belongs to the median (the percentage score of $1.66 \%$ ). Hence it was interpreted that most of the samples under study were between type of episiotomy incision of mediolateral. The above table shows the distribution samples according to their nutritional pattern. It shows that in frequency for 430 f the samples belongs to the vegetarian (the percentage score of 71.66\%); in the frequency for 17 of the samples belongs to the mixed (the percentage score of 28.33\%). Hence it was interpreted that most of the samples under study were vegetarian in type of nutritional pattern.

\section{Section B: Level of Assessment Of Episiotomy Wound Healing Among Postnatal Mothers From A.V.B.R.H.}

This section deals with level of assessment of episiotomy wound healing among postnatal mothers from AVBRH. 
The above table shows $71.66 \%$ of the postnatal mothers of anemia, 10\% of the have vulvovaginitis, $23.33 \%$ of had uninary tract infection, $1.66 \%$ of had surgical site infection, $8.33 \%$ of had perineal tear, $6.66 \%$ of had before episiotomy, 100\% of had after episiotomy, 1.66\% of had obesity, $11.66 \%$ of had hypothyrodium, $6.66 \%$ of had diabetes mellitus, 16.66 of had hypertension, $83.33 \%$ of had edema.

\begin{tabular}{|c|c|c|c|c|}
\hline Age (yrs) & $\begin{array}{c}\text { No. of } \\
\text { postnatal mothers }\end{array}$ & $\begin{array}{l}\text { Mean episiotomy } \\
\text { wound healing score }\end{array}$ & F-value & p-value \\
\hline $18-25$ yrs & 37 & $4.13 \pm 0.88$ & \multirow[t]{5}{*}{0.53} & \multirow{5}{*}{$\begin{array}{c}0.58 \\
N S, p>0.05\end{array}$} \\
\hline $26-30$ yrs & 21 & $4.42 \pm 1.39$ & & \\
\hline $30-35$ yrs & 2 & $4.50 \pm 0.70$ & & \\
\hline $35-40$ yrs & 0 & $0 \pm 0$ & & \\
\hline 40 \&t above & 0 & $0 \pm 0$ & & \\
\hline
\end{tabular}

Table 4. Association of episiotomy wound healing score among postnatal mothers in relation to their educational status $n=60$

\begin{tabular}{|l|c|c|c|c|}
\hline $\begin{array}{l}\text { Educational } \\
\text { Status }\end{array}$ & $\begin{array}{c}\text { No. of } \\
\text { postnatal } \\
\text { mothers }\end{array}$ & $\begin{array}{c}\text { Mean episiotomy } \\
\text { wound healing score }\end{array}$ & F-value & p-value \\
\hline Primary & 13 & $4.07 \pm 0.95$ & & \multirow{2}{*}{0.77} \\
\hline Secondary & 29 & $4.34 \pm 1.04$ & \multirow{2}{*}{0.54} \\
\hline Higher secondary & 8 & $4.50 \pm 1.05$ & & \\
\hline Graduate & 7 & $3.71 \pm 1.49$ & & \\
\hline $\begin{array}{l}\text { Post - graduate } \\
\text { Et above }\end{array}$ & 3 & $4.66 \pm 1.15$ & & \\
\hline
\end{tabular}

Table 5. Association of episiotomy wound healing score among postnatal mothers in relation to area of residence $n=60$

\begin{tabular}{|l|c|c|c|c|}
\hline Area of residence & $\begin{array}{c}\text { No. of } \\
\text { postnatal mothers }\end{array}$ & $\begin{array}{c}\text { Mean episiotomy } \\
\text { wound healing score }\end{array}$ & t-value & p-value \\
\hline Urban & 18 & $4.38 \pm 1.14$ & 0.54 & $\begin{array}{c}0.52 \\
\text { NS, p }>0.05\end{array}$ \\
\hline Rural & 42 & $4.19 \pm 1.06$ & & \\
\hline
\end{tabular}

Section C: Association Of Level Of Episiotomy Wound Healing Score Among Postnatal Mothers In Relation To Demographic Variables.

This table shows the association of episiotomy wound healing score with age in years of postnatal mothers. The tabulated ' $F$ ' values was 3.15( $\mathrm{df}=2,57)$ which is much higher than the calculated ' $F$ ' i.e. 0.53 at 5\% level of significance. Also the calculated ' $p$ ' $=0.58$ which was much higher than the acceptable level of significance i.e. ' $p$ ' $=0.05$. Hence it is interpreted that age in years of postnatal mothers is statistically not associated with their episiotomy wound healing score.
This table shows the association of episiotomy wound healing score with educational level of postnatal mothers. The tabulated ' $\mathrm{F}$ ' values was $2.52(\mathrm{df}=4,55)$ which is much higher than the calculated ' $F$ ' i.e. 0.77 at 5\% level of significance. Also the calculated ' $p$ ' $=0.54$ which was much higher than the acceptable level of significance i.e. 'p'=0.05. Hence it is interpreted that educational level of postnatal mothers is statistically not associated with their episiotomy wound healing score.

This table shows the association of episiotomy wound healing score with area of residence of postnatal mothers. The tabulated ' $t$ ' values was $2.00(\mathrm{df}=58)$ which 
is much higher than the calculated ' $t$ ' i.e. 0.54 at 5\% level of significance. Also the calculated ' $p$ ' $=0.52$ which was much higher than the acceptable level of significance i.e. ' $p$ ' $=0.05$. Hence it is interpreted that area of residence of postnatal mothers is statistically not associated with their episiotomy wound healing score.

\begin{tabular}{|c|c|c|c|c|}
\hline Occupation & $\begin{array}{l}\text { No. of } \\
\text { postnatal } \\
\text { mothers }\end{array}$ & $\begin{array}{l}\text { Mean episiotomy } \\
\text { wound healing score }\end{array}$ & F-value & p-value \\
\hline Housewife & 49 & $4.34 \pm 1.01$ & \multirow{4}{*}{2.77} & \multirow{4}{*}{$\mathrm{NS}, \mathrm{p}>0.05$} \\
\hline Private service & 1 & $2 \pm 0$ & & \\
\hline $\begin{array}{l}\text { Government } \\
\text { service }\end{array}$ & 0 & $0 \pm 0$ & & \\
\hline Others & 10 & $4 \pm 1.24$ & & \\
\hline
\end{tabular}

Table 7. Association of episiotomy wound healing score among postnatal mothers in relation to monthly income (Rs) $n=60$

\begin{tabular}{|c|c|c|c|c|}
\hline $\begin{array}{l}\text { Monthly } \\
\text { income(Rs) }\end{array}$ & $\begin{array}{c}\text { No. of } \\
\text { postnatal mothers }\end{array}$ & $\begin{array}{c}\text { Mean episiotomy } \\
\text { wound healing score }\end{array}$ & F-value & p-value \\
\hline $5000-10000$ & 31 & $4 \pm 1.12$ & \multirow{5}{*}{2.96} & \multirow{5}{*}{$\begin{array}{c}0.026 \\
\mathrm{~S}, \mathrm{p}<0.05\end{array}$} \\
\hline $10001-15000$ & 15 & $4.73 \pm 0.96$ & & \\
\hline $15001-20000$ & 6 & $4.83 \pm 0.75$ & & \\
\hline $20001-25000$ & 3 & $3 \pm 1$ & & \\
\hline $\begin{array}{l}30000 \mathrm{Et} \\
\text { above }\end{array}$ & 5 & $4.40 \pm 0.54$ & & \\
\hline
\end{tabular}

This table shows the association of episiotomy wound healing score with occupation of postnatal mothers. The tabulated ' $\mathrm{F}$ ' values was $3.15(\mathrm{df}=2,57)$ which is much higher than the calculated ' $F$ ' i.e. 2.77 at 5\% level of significance. Also the calculated ' $p$ ' $=0.071$ which was much higher than the acceptable level of significance i.e. 'p' $=0.05$. Hence it is interpreted that occupation of postnatal mothers is statistically not associated with their episiotomy wound healing score.

This table shows the association of episiotomy wound healing score with monthly family income(Rs) of postnatal mothers. The tabulated ' $F$ ' values was $2.52(\mathrm{df}=4,55)$ which is less than the calculated ' $\mathrm{F}$ ' i.e. 2.96 at $5 \%$ level of significance. Also the calculated 'p'=0.026 which was less than the acceptable level of significance i.e. ' $p$ ' $=0.05$. Hence it is interpreted that monthly family income(Rs) of postnatal mothers is statistically associated with their episiotomy wound healing score.

This table shows the association of episiotomy wound healing score with parity of postnatal mothers. The tabulated 't' values was $2.00(\mathrm{df}=58)$ which is much higher than the calculated 't' i.e. 1.04 at 5\% level of significance. Also the calculated ' $p$ ' $=0.30$ which was much higher than the acceptable level of significance i.e. ' $p$ ' $=0.05$. Hence it is interpreted that parity of postnatal mothers is statistically associated with their episiotomy wound healing score.

This table shows the association of episiotomy wound healing score with type of delivery of postnatal mothers. The tabulated 't' values was $2.00(\mathrm{df}=58)$ which is less than the calculated 't' i.e. 2.22 at 5\% level of significance. Also the calculated ' $p$ ' $=0.030$ which was less than the acceptable level of significance i.e. ' $p$ ' $=0.05$. Hence it is interpreted that type of delivery of postnatal mothers is statistically associated with their episiotomy wound healing score.

This table shows the association of episiotomy wound healing score with type of episiotomy incision of postnatal mothers. The tabulated 't' values was 2.00( $\mathrm{df}=58)$ which is much higher than the calculated ' $t$ ' i.e. 1.16 at $5 \%$ level of significance. Also the calculated ' $p$ ' $=0.24$ which was much higher than the acceptable level of significance i.e. 'p'=0.05. Hence it is interpreted that type of episiotomy incision of postnatal mothers is statistically not associated with their episiotomy wound healing score.

This table shows the association of episiotomy wound healing score with nutritional pattern of postnatal mothers. The tabulated 't' values was $2.00(\mathrm{df}=58)$ which is less than the calculated ' $t$ ' i.e. 2.71 at 5\% level of 
significance. Also the calculated 'p'=0.009 which was less than the acceptable level of significance i.e. 'p'=0.05. Hence it is interpreted that nutritional pattern of postnatal mothers is statistically associated with their episiotomy wound healing score.

Table 8. Association of episiotomy wound healing score among postnatal mothers in relation to parity $n=60$

\begin{tabular}{|l|c|c|c|c}
\hline Parity & $\begin{array}{c}\text { No. of } \\
\text { postnat mothers }\end{array}$ & $\begin{array}{c}\text { Mean episiotomy } \\
\text { wound healing score }\end{array}$ & F-value & p-value \\
\hline Primipara & 37 & $4.13 \pm 0.91$ & \multirow{2}{*}{1.04} & 0.30 \\
\hline Multipara & 23 & $4.43 \pm 1.30$ & & NS, $p>0.05$ \\
\hline Grandpara & 0 & $0 \pm 0$ & &
\end{tabular}

Table 9. Association of episiotomy wound healing score among postnatal mothers in relation to type of delivery $n=60$

\begin{tabular}{|l|c|c|c|c|}
\hline $\begin{array}{l}\text { Type of } \\
\text { Delivery }\end{array}$ & $\begin{array}{c}\text { No. of } \\
\text { postnatal } \\
\text { mothers }\end{array}$ & $\begin{array}{c}\text { Mean episiotomy } \\
\text { wound healing score }\end{array}$ & F-value & p-value \\
\hline $\begin{array}{l}\text { Spontaneous } \\
\text { labour }\end{array}$ & 44 & $4.05 \pm 0.99$ & \multirow{2}{*}{2.22} & \multirow{2}{*}{$5, p<0.030$} \\
\hline $\begin{array}{l}\text { Induced labour } \\
\text { Instrumental } \\
\text { delivery }\end{array}$ & 16 & $4.75 \pm 1.18$ & \\
\hline
\end{tabular}

Table 10. Association of episiotomy wound healing score among postnatal mothers in relation to type of episiotomy incision. $n=60$

\begin{tabular}{|l|c|c|c|c|}
\hline $\begin{array}{l}\text { Episiotomy } \\
\text { incision }\end{array}$ & $\begin{array}{c}\text { No. of } \\
\text { postnatal } \\
\text { mothers }\end{array}$ & $\begin{array}{c}\text { Mean episiotomy } \\
\text { wound healing score }\end{array}$ & F-value & p-value \\
\cline { 1 - 3 } Medio lateral & 59 & $4.27 \pm 1.08$ & \multirow{2}{*}{1.16} & \multirow{2}{*}{ NS,p [>0.05 } \\
\hline Median & 1 & $3 \pm 0$ & & \\
\hline Lateral & 0 & $0 \pm 0$ & $0 \pm 0$ & \\
\hline 'J' type & 0 & &
\end{tabular}

Table 11. Association of episiotomy wound healing score among postnatal mothers in relation to nutritional pattern $n=60$

\begin{tabular}{|l|c|c|c|c|}
\hline $\begin{array}{l}\text { Nutritional } \\
\text { Pattern }\end{array}$ & $\begin{array}{c}\text { No. of } \\
\text { postnatal } \\
\text { mothers }\end{array}$ & $\begin{array}{c}\text { Mean episiotomy } \\
\text { wound healing score }\end{array}$ & F-value & p-value \\
\hline SVegetarian & 43 & $4.02 \pm 1.01$ & \multirow{2}{*}{2.71} & \multirow{2}{*}{0.009} \\
\hline Non- vegetarian & 0 & $0 \pm 0$ & & S,p<0.05 \\
\hline Mixed & 17 & $4.82 \pm 1.07$ & \\
\hline
\end{tabular}

\section{DISCUSSION}

A non probability convenient sample of 60 subjects was drawn from the study population, who were from selected AVBRH Sawangi (Meghe) Wardha. The data obtained to describe the sample characteristics including age, education, Area of residence, number of parity, type of delivery, occupation, nutritional pattern, monthly income, type of episiotomy incision. The association of episiotomy wound healing score with age, educational level, area of residence, occupation and type of episiotomy incision of postnatal mothers is statistically not associated with their episiotomy wound healing score. 
The association of episiotomy wound healing score with monthly family income (Rs), parity, type of delivery and nutritional pattern of postnatal mothers is statistically associated with their episiotomy wound healing score. Uygur, Yesildalar, Kis \& Sisphi (2004) conducted a study on early repair of episiotomy dehiscence on 37 patients in Hanim maternity hospital, Turkey. Out of 37 patients, 12 patients were allowed to heal by secondary intention and 25 patients underwent early repair. All the episiotomies were medio-lateral. Infection was the obvious cause of dehiscence in 25 women. Among the patients treated by early repair, 3 patients had superficial separation of skin edges. The study concluded that with adequate pre- operative care, primarily wound cleansing and intravenous antibiotics, early repair of episiotomy dehiscence was safe and effective.

Demitrov, Tsenov (2000) conducted a prospective study on causes for healing complications in episiotomy on 33 puerperal women. The cases were divided into two groups: the first group were 12 women with normal healing of episiotomy and second group consists of 21 cases with wound healing complications, divided into 3 sub -groups:13 with edematous and erythematous edges; 5 with superficial dehiscence in the area of introitus vaginae and 3 with entirely open episiotomies. The study high lightened that episiotomy wound healing was influenced by age of the women, parity, duration of labour, and duration of rupture of membranes. Gracy, Limanowski, Wydukam (1998) conducted a comparative study on healing and patient comfort parameters between interrupted and subcutis polyglycolic acid suture used for episiotomy repair after delivery. Follow up was done during hospital stay, and two months after delivery. The data collection tool was self-administered questionnaire, enquiring about perineal pain, resumption of sexual intercourse and cosmetics of suture time. The study highlighted that at the 3rd day postpartum examination patients with sub cut is sutures had significantly better healing. 14

Hirsch (1997) article on episiotomy and its complications stated that median episiotomy, has a higher risk of third degree laceration. Medio-lateral episiotomy was followed by postpartum pain and impaired wound healing. For good healing of an episiotomy or a perineal laceration, suturing with non-reactive suture material is mandatory.A randomized controlled trial study was conducted to assess the effect of suture materials used in perineal repair undertaken by midwives with a sample of 391 women.The subjects were randomly allocated for repair with either polyglycolic acid (194) or chromic catgut (197). The study concluded that primiparity was a statistically significant predictor of pain, compared with multiparty at day $1(82.1 \%$ versus $65.3 \%)$ and day 3 (70.2\% versus 56.2\%). There was no statically significant difference in perineal pain between the two suture materials at any time point, with and without parity adjustment.

Implication: The findings of the study have several implications for nursing practice, nursing administration, nursing education and nursing research.

Nursing Practice: The nurse plays a vital and major role in the healthcare delivery system. Nurse midwives have an important role to play in the care of perineal trauma due to episiotomy. She is the one who works in the immediate environment with the patients and hence she has all the opportunity to identify the needs and problems. Each nurse midwife should provide one to one comprehensive care to clients to prevent long term puerperal complications. There is a need for the nurses to teach the clients about perineal hygiene and the factors responsible of episiotomy wound healing. If women are given a clear explanation of the self-care, they tend to do it well. Perineal care is an easy procedure to learn and the mother can be instructed to carry it out herself as soon as she is ambulatory.

Nursing Administration: Nursing administration improves economic and social standards. It contributes to the healthy economy of a hospital or institution by making effective utilization of its resources and bringing fair returns on investment. The nursing administration should look into the need for organizing in-service and continuing nursing education programs for staff nurses in order to update their knowledge regarding episiotomy care. Nursing administration must awaken to the fact that patient education is a necessity and should provide resources in terms of manpower, money and material.

Nursing Education: The nurses will need assessment skills, technical competence and the ability to deal with the rapid changes in the environment. The knowledge base and technology used in providing nursing care will continue to increase as well as the nurse's need for skill and ability. Nursing curriculum should be equipped with knowledge and skills to prepare efficient and skillful nurses to provide quality nursing care. Nursing students should be given updated knowledge on recent practices and trends of episiotomy care. Nurses will be required to provide more in-depth education on self-care practices to patients. Educator will help students, colleagues and junior staff to be trained using the awareness about the episiotomy wound healing.

Nursing Research: Use of research findings should become a part of the quality assurance evaluation to evaluate individual performance as a whole. The study will motivate initial researchers to conduct the study on large scale selected care measures to protect the perineum may reduce the maternal morbidity. It is a topic that requires further evaluation through well designed and implemented research.

\section{Recommendations:}

1. The same study could be undertaken with larger samples to show strong statistical associations.

2. The similar study can be conducted on Selective episiotomy vs. implementation of a non-episiotomy protocol: a randomized clinical trial 
3. Pattern of episiotomy use \& its immediate complications among vaginal deliveries in tertiary care hospitals and or various setting.

4. Episiotomy Practice: Changes and Evidence-based Practice

5. Comparison: Policy of selective/restrictive compared with routine or liberal use of episiotomy.

\section{CONCLUSION}

After normal vaginal delivery the mother has to adjust to physical changes in her own body due to involution and lactation. She also has to come up with the new demands on her time and emotions made by the new born baby. The discomfort of episiotomy is an added concern in the already overstressed situation. Episiotomy, despite evidence that it is an unnecessary intervention, is one of the most common surgical procedures performed during the second stage of labour especially in Primigravide women. Perineal trauma due to episiotomy causes a number of distressing conditions in the postnatal period. It causes pain, discomfort, disturbed normal activities; it gives the mother a feeling of inadequacy, increased the risk of infection, prolongs postnatal recovery and increased the cost of healthcare. After the detailed analysis, this study leads to following conclusion. It empowers a mother with the ability to do her normal activities earlier than normal. It also decreases the risk of infection by increasing vascularity, enhances quick recovery and shortens the hospitalization period and thereby minimizing the healthcare cost.

Ethical Approval: Approved by Institutional Ethical committee on 12/10/2019.the reference No. is DMIMS (DU)/IEC/Sept-2019/8497.

Patient inform Consent: Informed consent has been taken at the time of data collection.

Conflict of Interest: The Author declares that there are no conflicts of interest.

Funding: Not applicable.

\section{REFERENCES}

Amorim MM F-NA, Leal NV, Melo FO, et al. Is It Possible To Never Perform Episiotomy During Vaginal Delivery? Obstet Gynecol.2014;123(Suppl 1):38S.

Borruto F CC. Episiotomy: A Too Often Unnecessary And Harmful Practice. MOJ Women's Health. 2016;2(1):00020.3.

Chaithra. Episiotomy in Primigravida Routine Versus Selective At Chevalumba Hospital Mysore. Mmed Dissertation. 2012.

Chochrane library, Episiotomy for vaginal birth, Cochrane Systematic Review - Intervention Version published: 21 January 2009, https://doi.org/10.1002/14651858. CD000081.pub2

D’Gregorio P. Obstetric Violence: A New Legal Term
Introduced In Venezuela. Int J Gynaecol Obstet. 2010;111:201-202.9.

Dr.Swati Rathod, Associate Professor, Department of Obstetrics and Gynaecology, 7th Floor, ISSCC Building, Risk Factors for Peripartum Wound Dehiscence, Journal of Clinical and Diagnostic Research, 2018, Nov, Vol-12(11): QC08-QC11 9 Christian Medical College and Hospital, Vellore-632004, Tamil Nadu, India. E-mail: coronistrial@yahoo.co.in DOI: 10.7860/ JCDR/2018/37763.12232

El-Nagger Mha. Effect Of Self Perineal Care Instructions On Episiotomy Pain And Wound Healing Of Postpartum Women. Journal Of American Science. 2012;8(6):6406550.

Episiotomy. Available at URL:http://www.en.wikipedia. org/html. Accessed November15, 2012.

Graham Ian D, Carroli G, Davies C, et al. Episiotomy Rates Around the World: An Update. Birth. 2005;32(3):219223.

Jacob A. A comprehensive textbook of midwifery. 2nd ed. New Delhi: Jaypee Brother's medical publishers; 2005. P 196-97.

Michel S. A comparative study to assess the effectiveness of sitzbath versus self perineal care on episiotomy wound healing among postnatal mothers in Jayanagar general hospital, Bangalore south.[postgraduate dissertation]. Karnataka: Rajiv Gandhi University of Health sciences; 2006 [cited 2012 Dec 17].Available from: http://hdl.handle.net/123456789/2830.

Mohamed HA, Nagger NS. Effect of self perineal care instructions on episiotomy pain and wound healing of postpartum women. Journal of American science [serial online] 2012;8(6):640-50. (ISSN: 1545- 1003). Available from URL:http://www.americanscience.org.79. Accessed November15, 2012.

Normal and abnormal pueperium. Available at URL:http://emedicine. medscape.com/article/260187overview. Accessed November15 2012.

Nursing and Midwifery College, Arak University of Medical Sciences, Arak, Tehran, Iran. swt_f@yahoo. com Healing advantages of lavender essential oil during episiotomy recovery: a clinical trial. DOI: 10.1016/j. ctcp.2010.05.006

Pankaj desai, current obstetrics \& gynecology practice,(1st edition) jaypee brother publication, 2005, New Delhi, Pp 99-102

Perineum. Medical dictionary. The free dictionary. com. Available at URL:http://www.google.co.in/html. Accessed November15, 2012.

Priya PR. Cost effectiveness of self perineal care versus aseptic perineal care upon episiotomy wound healing among postnatal mothers in selected hospital at chenna. Available from URL:http://www.mptnai.org/ 
researchabstract. Accessed November15, 2012.

Richard E. Allen, MD, MPH, and Ronald W. Hanson Jr, MD, Episiotomy in Low-Risk Vaginal Deliveries, Am Board Fam Pract: first published as 10.3122/jabfm, January-February 2005 Vol. 18 No. 1,Doi:- http://www. jabfp.org.

Rudman A, Waldenstorm U. Critical views on postpartum care expressed by new mothers. BMC Health Services Research [serial online] 2007, 7:178.Available from URL: http://www.biomedcentral.com/1472-6963/7/178. Accessed on November15, 2012.

Stephanie Brown. Caring of your perineum. Available at URL:http://Babyparenting.about.com/ cs/postpartumissues/a/perinealcare. Accessed on
November15, 2012.

Sukanya. A study to evaluate the effectiveness of self instructional module for primipara postnatal mothers regarding perineal care at selected hospitals of Bangalore [postgraduate dissertation]. Karnataka: Rajiv Gandhi University of Health Science; 2005[cited 2012 Nov 15].

Thacker SB, Banta HD. Benefits And Risks of Episiotomy: An Interpretative Review Of The English Language Literature, 1860-1980. Obstet Gynecol Surv. 1983;38(6):322-338.

Usha Dssadv. A Clinical Study of Agaruvadi Yoni Dhupana on Episiotomy Wound. European Journal of Biomedical and Pharmaceutical Sciences. 2016;3(3):322327.2. 